\title{
Effect of Copper and Tin on Hot Ductility of Ultra-low and 0.2\% Carbon Steels
}

\author{
Chihiro NAGASAKI and Junji KIHARA
}

Department of Metallurgy, School of Engineering, The University of Tokyo, Hongo, Bunkyo-ku, Tokyo, 113 Japan.

(Received on November 1, 1996; accepted in final form on January 14, 1997)

\begin{abstract}
The hot ductility of ultra-low carbon steels and $0.2 \%$ plain carbon steels containing copper and/or tin has been investigated at elevated temperatures ranging from ferrite region to lower austenite region and at various strain rates. Ultra-low carbon steels generally exhibit good ductility regardless of copper and tin additions except for the lower austenite temperature range, where the addition of tin decreases the ductility slightly. The plain carbon steel containing $1.0 \%$ copper also exhibits good ductility, except for a ductility trough around $1050 \mathrm{~K}$ and at $10^{-2} \mathrm{~s}^{-1}$. Recrystallization results in the improvement of ductility above $1180 \mathrm{~K}$ and at $10^{-2} \mathrm{~s}^{-1}$. The plain carbon steel containing $0.2 \%$ tin shows good ductility at $200 \mathrm{~s}^{-1}$, but exhibits a ductility trough in the lower austenite temperature range below $1 \mathrm{~s}^{-1}$. At the strain rate of $10^{-2} \mathrm{~s}^{-1}$, the embrittlement takes place most severely at $1080 \mathrm{~K}$, which corresponds to the transition temperature from austenite to ferrite. The embrittlement with intergranular fracture occurs in the specimen with low reduction in area. Initial cracking is observed at grain boundaries without proeutectoid ferrite. The addition of tin can prevent grain boundary migration or dynamic recrystallization by its grain boundary segregation, which leads to decrease in ductility.
\end{abstract}

KEY WORDS: steel scraps; hot ductility; ultra-low carbon steel; grain boundary segregation; vacancy diffusion; grain boundary migration; copper; tin; sulphur.

\section{Introduction}

The recycling of steel scraps is an important subject for protecting global environment. The scraps usually contain tramp elements such as copper, tin, lead, antimony and arsenic, which could have a detrimental effect on the mechanical properties of steels. ${ }^{1,2)}$ Particularly, slabs made from scraps have faults in hot workability, causing crack formation during hot working processes such as high speed casting and hot direct rolling. While most tramp elements can be eliminated by steelmaking processes, but copper and tin cannot be completely eliminated by the present technique. Therefore, the hot workability of steels containing copper and tin should be investigated; and factors controlling the workability and the method for improvement must be examined.

The previous papers ${ }^{3-7}$ have shown that oxygen and sulphur are detrimental to the hot ductility. It is concluded, in some reports, ${ }^{6-10)}$ that tin, copper, antimony and arsenic are also detrimental to the ductility. However, the effect of oxygen, sulphur and phosphorous on ductility is superimposed on that of copper and tin since the steels tested have higher contents of oxygen, sulphur and phosphorous. Hence, the effect of copper and tin on ductility has not be evaluated precisely. Furthermore, the hot ductility of steels containing current oxygen and sulphur contents should be examined.

In this paper, the hot ductility of ultra-low carbon steels and $0.2 \%$ plain carbon steels was investigated by tensile test in a wide range of strain rates in vacuum. The effect of copper, tin, and sulphur on hot ductility was also studied. For the ultra-low carbon steels, the ductility was investigated at the elevated temperatures ranging from the higher ferrite to the austenite, and, for $0.2 \%$ carbon steels, from the higher ferrite-pearlite to the austenite containing austenite-ferrite dual phase region.

\section{Experimental Procedure}

\subsection{Materials}

The chemical compositions of the carbon steels used in this study are shown in Table 1. The steels A, B, $\mathrm{C}, \mathrm{D}, \mathrm{E}$, and $\mathrm{F}$ are ultra-low carbon steels containing $0.001 \%$ carbon. The high purity steels $\mathrm{A}, \mathrm{B}, \mathrm{C}$, and $\mathrm{D}$, sulphur contents of which are little, were employed in order to investigate the effect of the addition of copper and/or tin. The steels $\mathrm{O}, \mathrm{P}, \mathrm{Q}$, and $\mathrm{R}$ are carbon steels containing $0.2 \%$ carbon. The steel $\mathrm{O}$ and the steel $\mathrm{P}$ contain $1.0 \%$ copper and $0.2 \%$ tin, respectively. The steels $\mathrm{E}, \mathrm{F}, \mathrm{Q}$, and R containing the high sulphur content, that was previous level, were employed to examine the effect of copper on ductility. All of these steels were cast in vacuum and hot-rolled at the temperature of 1173 to $1223 \mathrm{~K}$ to plates of thickness $20 \mathrm{~mm}$ by multi-passes. They were hot-rolled at $1073 \mathrm{~K}$ to plates of thickness $13 \mathrm{~mm}$, cut to square bars of $13 \mathrm{~mm}$, and then cold-swaged to rods of diameter $8.8 \mathrm{~mm}$. Tensile 
Table 1. Chemical compositions of carbon steels used. (mass\%)

\begin{tabular}{cccccccc}
\hline & $C$ & $S i$ & $M n$ & $P$ & $S$ & $C u$ & $S n$ \\
\hline A & 0.0014 & $<0.01$ & $<0.01$ & $<0.001$ & 0.0011 & $<0.01$ & - \\
B & 0.0014 & $<0.01$ & $<0.01$ & $<0.001$ & 0.0011 & 0.51 & - \\
C & 0.0010 & $<0.01$ & $<0.01$ & $<0.001$ & 0.0011 & $<0.01$ & 0.08 \\
D & 0.0016 & $<0.01$ & $<0.01$ & $<0.001$ & 0.0012 & 0.50 & 0.08 \\
E & 0.0005 & 0.01 & $<0.01$ & 0.001 & 0.0032 & - & - \\
F & 0.0005 & $<0.01$ & $<0.01$ & 0.001 & 0.004 & 0.49 & - \\
O & 0.18 & 0.04 & 0.035 & $<0.001$ & 0.0008 & 0.98 & $<0.001$ \\
P & 0.18 & 0.02 & 0.035 & $<0.001$ & 0.0008 & 0.008 & 0.192 \\
$Q$ & 0.19 & $<0.01$ & $<0.01$ & 0.001 & 0.003 & 0.003 & - \\
$\mathrm{R}$ & 0.20 & $<0.01$ & $<0.01$ & 0.001 & 0.004 & 0.50 & - \\
\hline
\end{tabular}

specimens were machined from the rods after annealing for $3600 \mathrm{~s}$ at $1223 \mathrm{~K}$. The gauge length and diameter are 10 and $6 \mathrm{~mm}$, respectively.

\subsection{Tensile Test}

Tensile testing was conducted at $7 \times 10^{-2} \mathrm{~Pa}$ or higher in vacuum by the tensile machine with wide range of loading speeds. ${ }^{9)}$ Specimens were deformed between 880 and $1380 \mathrm{~K}$ at the strain rates of $10^{-2}, 1$, and $200 \mathrm{~s}^{-1}$. The specimens solution-treated at $1630 \mathrm{~K}$ for $120 \mathrm{~s}$ were cooled at $10 \mathrm{~K} / \mathrm{s}$ down to and then held for $60 \mathrm{~s}$ at each testing temperature.

\subsection{Microstructure Observation}

The fracture surfaces were observed by scanning electron microscopy (SEM). The longitudinal sectional microstructures were observed by optical microscopy $(\mathrm{OM})$ on the specimens quenched at the cooling rate of $70 \mathrm{~K} / \mathrm{s}$ by helium gas after they were deformed to the strains of 0.10 to 0.25 . Auger electron spectroscopy (AES) was used on intergranular fracture surfaces in order to investigate grain boundary segregation.

\section{Results}

\subsection{Hot Ductility of Ultra-low Carbon Steels}

The specimens of ultra-low carbon steels containing copper and/or tin were deformed at $10^{-2}, 1$ and $200 \mathrm{~s}^{-1}$. The variations of reduction in area with temperature at 1 and $200 \mathrm{~s}^{-1}$ are shown in Figs. 1 and 2, respectively. The steel containing copper and the steel containing neither copper nor tin exhibit good ductility, showing reduction in area of $80 \%$ and more throughout the temperature range at each strain rate. For the steel containing tin, the ductility decreases only at $1230 \mathrm{~K}$ or above the transition temperature from austenite to ferrite at the strain rates of 1 and $200 \mathrm{~s}^{-1}$, while the ductility deformed at $10^{-2} \mathrm{~s}^{-1}$ is good throughout the temperature range investigated. For the steel containing copper and tin, the reduction in area is $60 \%$ at $1230 \mathrm{~K}$ for $10^{-2}$ and $1 \mathrm{~s}^{-1}$ and it is $70 \%$ at 1230 and $1280 \mathrm{~K}$ for $200 \mathrm{~s}^{-1}$. All of the steels show good ductility in the ferrite temperature range of $1180 \mathrm{~K}$ and bellow and in the austenite temperature range of $1330 \mathrm{~K}$ and above.

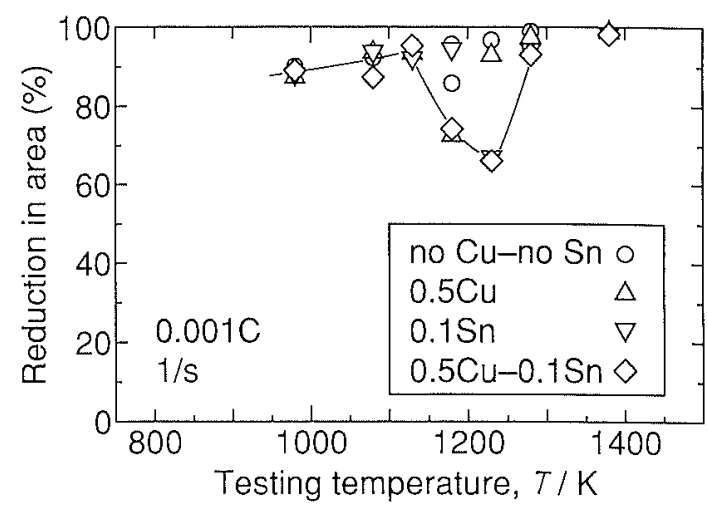

Fig. 1. Hot ductility for the high purity ultra-low carbon steels containing copper and/or tin deformed at $1 \mathrm{~s}^{-1}$.

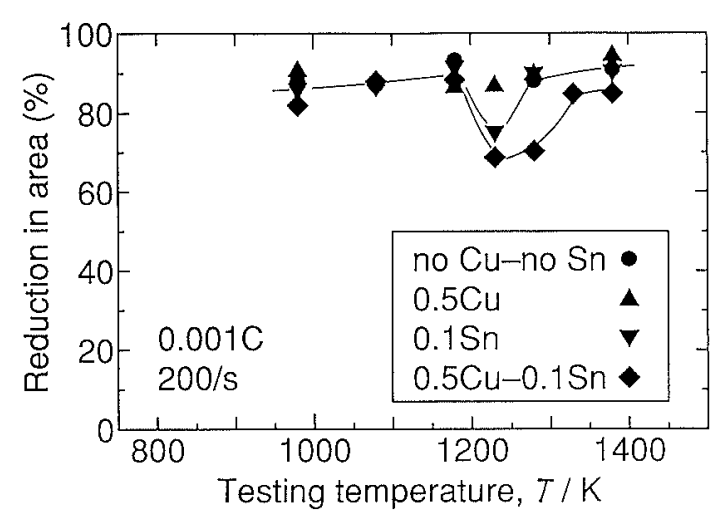

Fig. 2. Hot ductility for the high purity ultra-low carbon steels containing copper and/or tin deformed at $200 \mathrm{~s}^{-1}$.

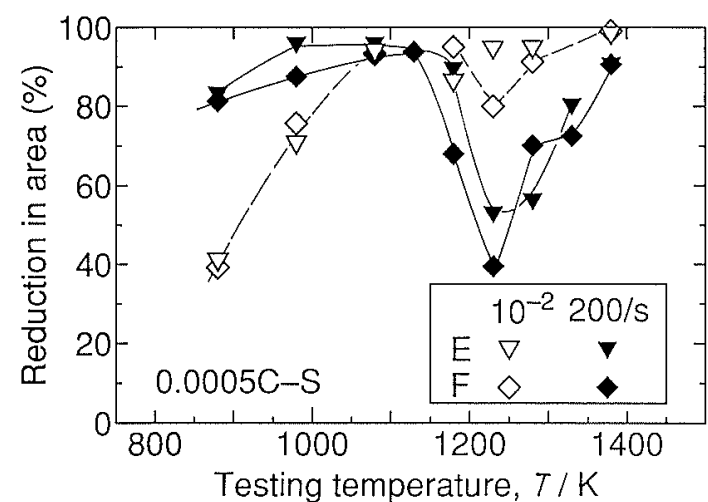

Fig. 3. Effect of copper on the hot ductility of ultra-low carbon steels containing $0.004 \%$ sulphur deformed at $10^{-2}$ and $200 \mathrm{~s}^{-1}$.

The steels containing $0.004 \%$ sulphur were deformed at $10^{-2}$ and $200 \mathrm{~s}^{-1}$. The effect of copper addition on the hot ductility is shown in Fig. 3. Both steels exhibit good ductility in the temperature range of higher ferrite to lower austenite at $10^{-2} \mathrm{~s}^{-1}$. The reduction in area deformed at $200 \mathrm{~s}^{-1}$ is decreased with decreasing of temperature between 1380 and $1230 \mathrm{~K}$, where it reaches a minimum. Then it increases rapidly with further decrease in temperature, and it is $90 \%$ or higher at the temperatures of $1130 \mathrm{~K}$ and below. The addition of copper causes the reduction in area to decrease from 53 to $40 \%$ at $1230 \mathrm{~K}$ and promotes the embrittlement in the lower austenite temperature range. Except for this temperature, the addition of $0.5 \%$ copper is not det- 
rimental to the ductility in the temperature range of higher ferrite to lower austenite. In the case of $200 \mathrm{~s}^{-1}$, the steel containing $0.001 \%$ sulphur exhibits good ductility, while the steel containing $0.004 \%$ sulphur exhibits low ductility at 1180 to $1330 \mathrm{~K}$, which is the lower austenite temperature range. The addition of sulphur decreases the ductility at high strain rate in the lower austenite temperature range.

It is concluded that the ductility of the ultra-low carbon steel containing copper and tin decreases in the lower austenite temperature range. The ductility of the steels is excellent in the other austenite temperature range and the ferrite temperature range; copper and tin have a small effect on the hot ductility. The steel containing sulphur has low ductility at the lower austenite temperature range at high strain rate regardless of the copper addition.

\subsection{Hot Ductility of Plain Carbon Steels}

The variation of reduction in area with temperature for the $0.2 \%$ carbon steel containing $1.0 \%$ copper (steel $\mathrm{O})$ is shown in Fig. 4. The reduction in area deformed at $200 \mathrm{~s}^{-1}$ is high throughout the temperature range. For the specimens deformed at $10^{-2} \mathrm{~s}^{-1}$, the ductility decreases around $1050 \mathrm{~K}$, which is the transition temperature from austenite to ferrite.

The variation of reduction in area with temperature for the $0.2 \%$ carbon steel containing $0.2 \%$ tin (steel P) is shown in Fig. 5. The steel shows good ductility throughout the temperature range for $200 \mathrm{~s}^{-1}$. For the specimen deformed at $10^{-2} \mathrm{~s}^{-1}$, the reduction in area is about $100 \%$ at $1380 \mathrm{~K}$ and above, and decreases with

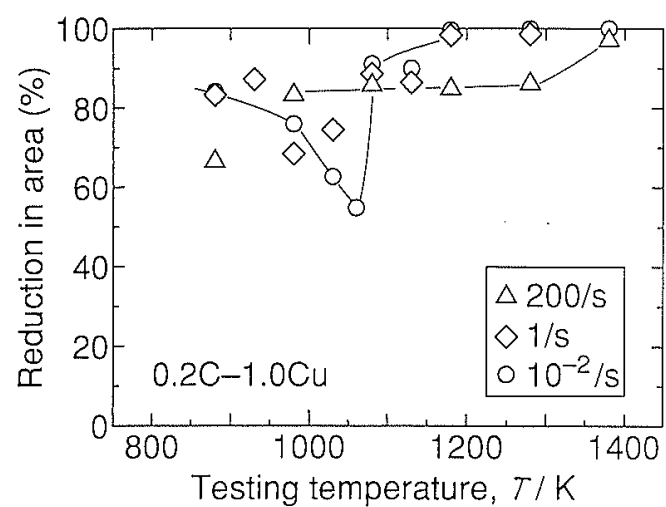

Fig. 4. Hot ductility for the $0.2 \%$ carbon steel containing $1.0 \%$ copper $\mathrm{O}$ deformed at $10^{-2}, \mathrm{~L}$ and $200 \mathrm{~s}^{-1}$

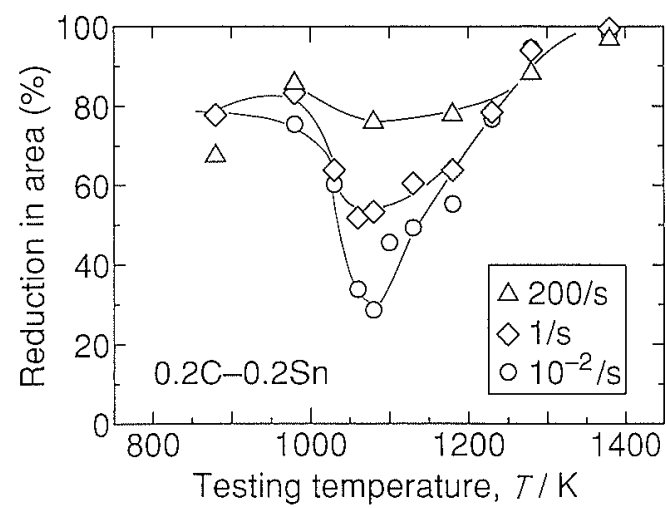

Fig. 5. Hot ductility for the $0.2 \%$ carbon steel containing $0.2 \%$ tin $\mathrm{P}$ deformed at $10^{-2}, 1$ and $200 \mathrm{~s}^{-1}$. decreasing temperature. The embrittlement occurs between 1030 and $1180 \mathrm{~K}$ and the minimum reduction in area is $32 \%$ at $1080 \mathrm{~K}$. Then the ductility improves rapidly with further decrease in temperature. It can be seen clearly in Fig. 5 that the ductility decreases with decreasing strain rate in the brittle temperature range between ferrite formation and lower austenite.

The ductility of the $0.2 \%$ carbon steel containing $0.5 \%$ copper and $0.004 \%$ sulphur (steel R) is shown in Fig. 6. For the specimen deformed at $200 \mathrm{~s}^{-1}$, the reduction in area decreases with decreasing temperature at $1380 \mathrm{~K}$ and below. It is $40 \%$ at the lower austenite temperature of $1180 \mathrm{~K}$. It increases rapidly with further decrease in temperature, and the ductility is good at the $\mathrm{Ar}_{3}$ temperature of $1130 \mathrm{~K}$. The reduction in area is $60 \%$ in the low austenite temperature range between 1030 and $1130 \mathrm{~K}$ at $10^{-2} \mathrm{~s}^{-1}$. After isothermal holding for $600 \mathrm{~s}$ at $1280 \mathrm{~K}$ on the way cooling from the solution treatment temperature, the reduction in area increases from 33 to $67 \%$ in the specimen deformed at $1180 \mathrm{~K}$ and at $200 \mathrm{~s}^{-1}$.

The effect of copper on the ductility was negligible small by comparing the steels $\mathrm{Q}$ and $\mathrm{R}$, which contain $0.004 \%$ sulphur. The reduction in area for both steels was about the same in the austenite temperature range at $10^{-2}$ and $200 \mathrm{~s}^{-1}$. Sulphur decreases the ductility in the lower austenite temperature range. Copper has a small effect on the ductility of the steel containing sulphur.

It is concluded that the ductility of the plain carbon steel containing copper decreases at the $\mathrm{Ar}_{3}$ temperature and at lower strain rates. The steel containing tin shows a ductility trough from the $\mathrm{Ar}_{3}$ temperature up to lower austenite temperatures at lower strain rates. Sulphur decreases the ductility at the lower austenite temperatures and at all strain rates.

\subsection{Fractography}

Austenite intergranular fracture was observed by SEM in the brittle fracture surfaces. Depending on the morphology of the fracture surface, intergranular fracture surfaces can be classified into three types; (1) a smooth fracture surface having no dimples, which is called intergranular decohesion fracture surface, (2) a fracture surface that contains fine dimples with the diameter of about $1 \mu \mathrm{m}$, which is called intergranular dimple fracture surface, and (3) a fracture surface ac-

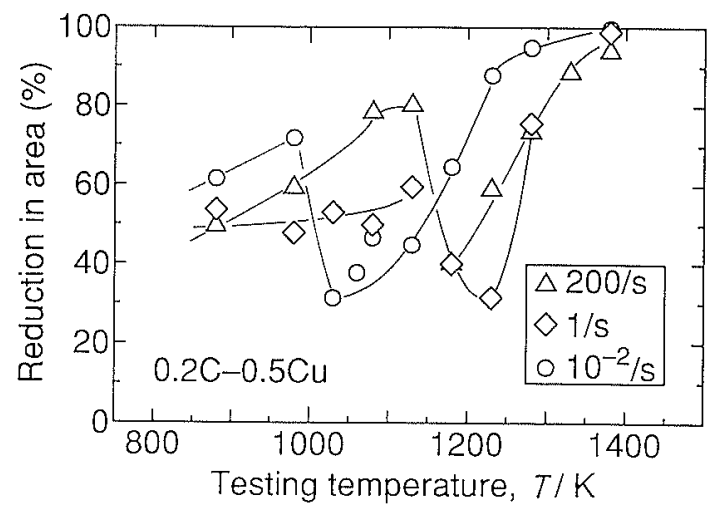

Fig. 6. Hot ductility for the $0.2 \%$ carbon steel containing $0.5 \%$ copper $\mathrm{R}$ deformed at $10^{-2}, 1$ and $200 \mathrm{~s}^{-1}$ 

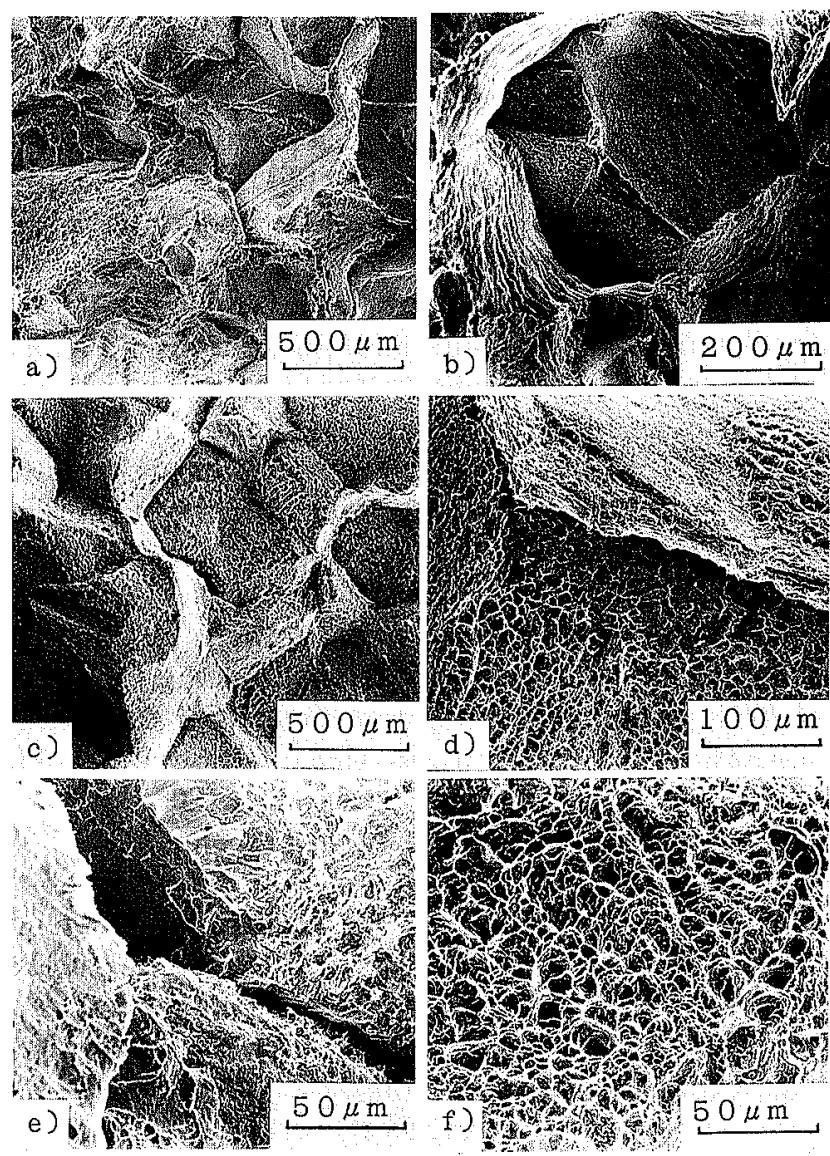

Fig. 7. Fracture surfaces of the $0.2 \%$ carbon steel $P$ (SEM); a), b) deformed at $1060 \mathrm{~K}$ and at $1 \mathrm{~s}^{-1}$; RA=52\%, c), d), e), f) deformed at $1080 \mathrm{~K}$ and at $10^{-2} \mathrm{~s}^{-1}$; RA $=29 \%$.

companied with deformation of grains, which is called intergranular ductile fracture surface.

Fracture surfaces of the $0.2 \%$ carbon steel $\mathrm{P}$ were observed at the temperatures where the reduction in area is the minimum at each strain rate, as shown in Fig. 7. Intergranular decohesion fracture is observed for $1 \mathrm{~s}^{-1}$, and intergranular dimple fracture and intergranular ductile fracture are observed for $10^{-2} \mathrm{~s}^{-1}$.

Fracture surfaces of the $0.2 \%$ carbon steel $\mathrm{R}$ were observed at the temperature where the reduction in area is the minimum at each strain rate, as shown in Fig. 8. Intergranular decohesion fracture is observed for 1 and $200 \mathrm{~s}^{-1}$, and intergranular ductile fracture is observed for $10^{-2} \mathrm{~s}^{-1}$. Intergranular cracking is observed for 1 and $10^{-2} \mathrm{~s}^{-1}$. The fracture surface of the steel $\mathrm{Q}$ is comparable with that of the steel $\mathrm{R}$.

The intergranular decohesion fracture was observed on the fracture surfaces with low ductility deformed at $200 \mathrm{~s}^{-1}$ for the ultra-low carbon steels $\mathrm{E}$ and $\mathrm{F}$, whereas intergranular ductile fracture and many intergranular cracks are observed on the fracture surfaces at $1 \mathrm{~s}^{-1}$ for the steel $\mathrm{F}$.

Therefore, intergranular decohesion fracture takes place for $200 \mathrm{~s}^{-1}$, and, with decrease in strain rate, it is translated to intergranular ductile fracture and the crack at the grain boundary appears.
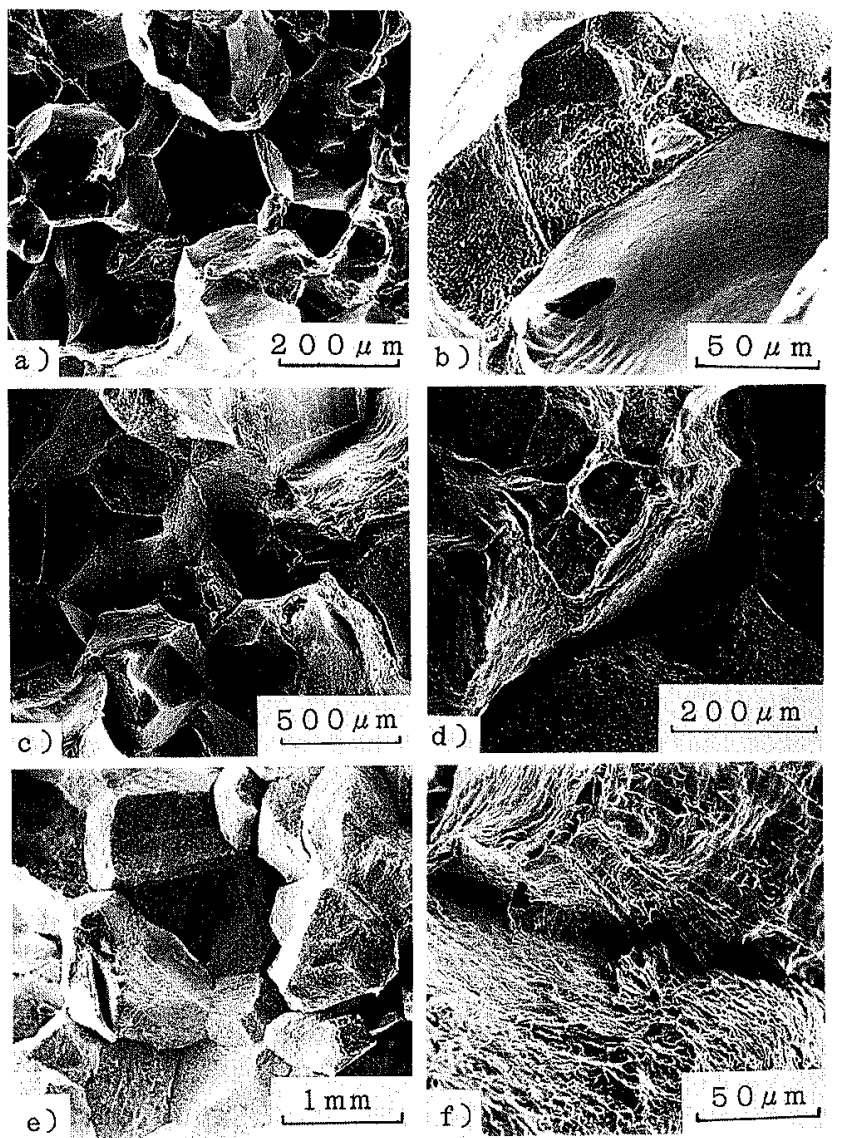

Fig. 8. Fracture surfaces of the $0.2 \%$ carbon steel R (SEM); a), b) deformed at $1180 \mathrm{~K}$ and at $200 \mathrm{~s}^{-1} ; \mathrm{RA}=44 \%$, c), d) deformed at $1230 \mathrm{~K}$ and at $1 \mathrm{~s}^{-1} ; \mathrm{RA}=31 \%$, e), f) deformed at $1030 \mathrm{~K}$ and at $10^{-2} \mathrm{~s}^{-1} ; \mathrm{RA}=31 \%$.

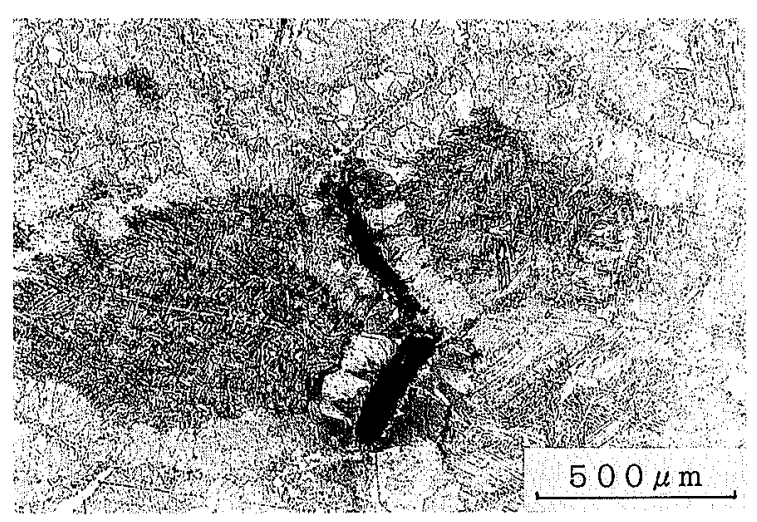

Fig. 9. Deformation microstructures for the $0.2 \%$ carbon steel $P$ deformed to the strain of 0.21 at $1080 \mathrm{~K}$ and at $10^{-2} \mathrm{~s}^{-1}$

\subsection{Deformation Structure}

The longitudinal sectional microstructures developed during hot deformation were observed by an optical microscope. The microstructures of the steel $\mathrm{P}$, deformed to the strain of 0.21 at $1080 \mathrm{~K}$ and at $10^{-2} \mathrm{~s}^{-1}$, are shown in Fig. 9. The straight crack initiated along the austenite grain boundary grows with increasing strain. The filmlike ferrite was observed along the grain boundaries, and the crack is not initiated at the ferrite.

The microstructures of the steel $\mathrm{R}$ deformed at 1130 and $1030 \mathrm{~K}$ and at $10^{-2} \mathrm{~s}^{-1}$ are shown in Fig. 10. The 


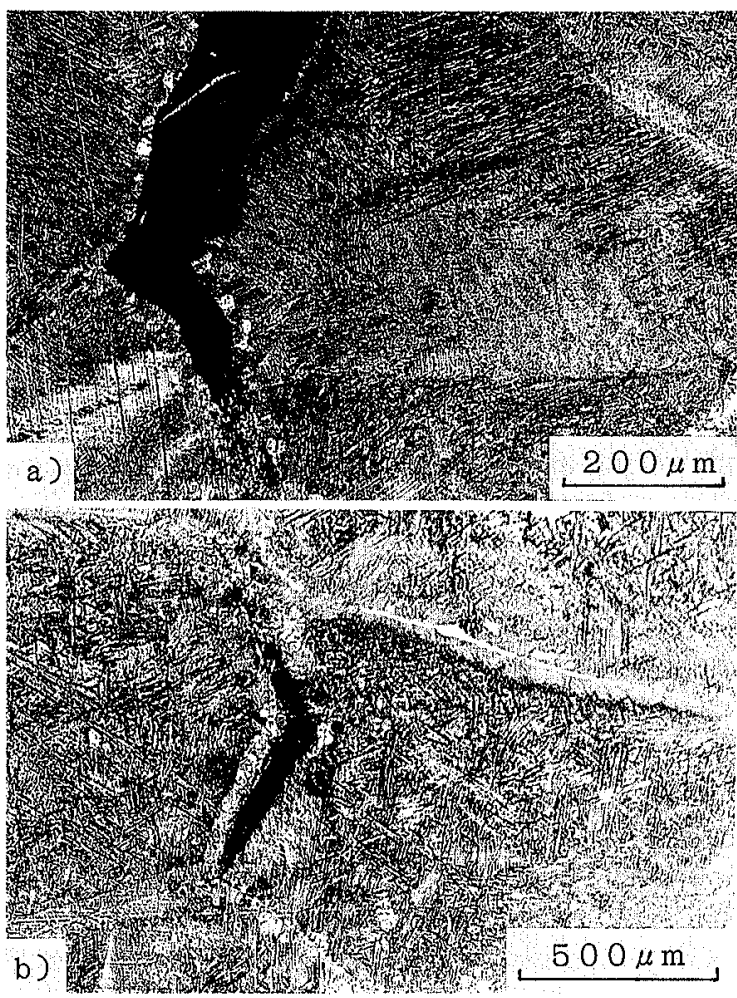

Fig. 10. Deformation microstructures for the $0.2 \%$ carbon steel $R$ deformed at $10^{-2} \mathrm{~s}^{-1}$; a) the strain of 0.20 at $1130 \mathrm{~K}$ and $\mathrm{b}$ ) the strain of 0.16 at $1030 \mathrm{~K}$.

straight crack is initiated along the austenite grain boundary, and ferrite grains are observed in the vicinity of the crack at the strain of 0.20 at $1130 \mathrm{~K}$. The ferrite is supposed to be formed during cooling since this temperature is above the $\mathrm{Ae}_{3}$ temperature of $1100 \mathrm{~K}$. The film-like ferrite is formed along the austenite grain boundaries at the strain of 0.16 at $1030 \mathrm{~K}$. However, no ferrite is observed on the grain boundary along which the straight crack is initiated.

It is observed that all of the cracks initiate and propagate along the austenite grain boundaries in the brittle specimen. No crack was, however, detected on film-like ferrite formed along the grain boundaries at low strain rates.

\subsection{Auger Electron Spectroscopy Analysis on Grain Boundary}

The intergranular fracture surfaces were analyzed by AES. Auger spectrum at the surface of intergranular ductile fracture for the steel $\mathrm{P}$, deformed at $1100 \mathrm{~K}$ and at $10^{-2} \mathrm{~s}^{-1}$, is shown in Fig. 11. Iron, tin, carbon, chlorine and oxygen are detected at the surface. Carbon, oxygen and chlorine are contaminants since their concentration decreases monotonously with sputtering. The distribution of tin content through the depth from the grain boundary surface by $\mathrm{Ar}^{+}$ion sputtering at the rate of $0.2 \mathrm{~nm} / \mathrm{s}$ is shown in Fig. 12. After the contamination layer was eliminated, the tin content on the grain boundary surface $X_{\mathrm{Sn}}^{\mathrm{g}}$ is $21 \mathrm{~mol} \%$ and tin is segregated with thickness of $4 \mathrm{~nm}$ or ten atomic layers at the grain boundary. Total tin volume per unit area of the grain boundary $Y_{\mathrm{Sn}}^{\mathrm{g}}$ is estimated to be $1.2 \times 10^{-7} \mathrm{~mol} \% \mathrm{~m}$.

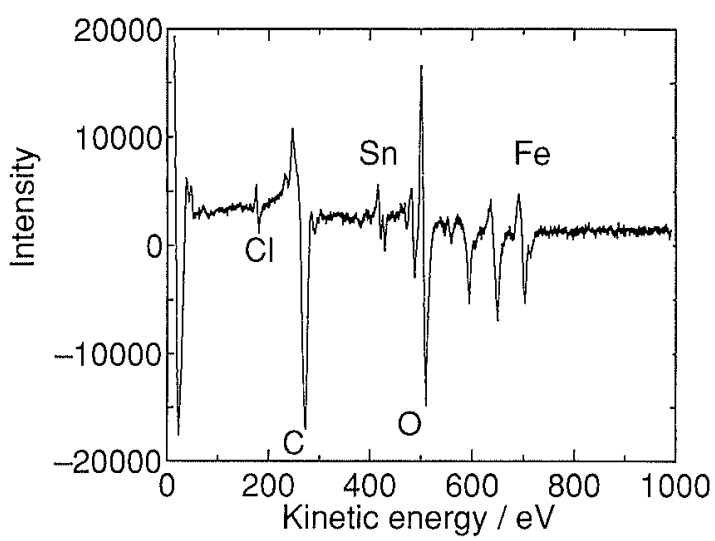

Fig. 11. Auger spectrum on grain boundary of fracture surface, for the steel $\mathrm{P}$ deformed at $1100 \mathrm{~K}$ and at $10^{-2} \mathrm{~s}^{-1}$.

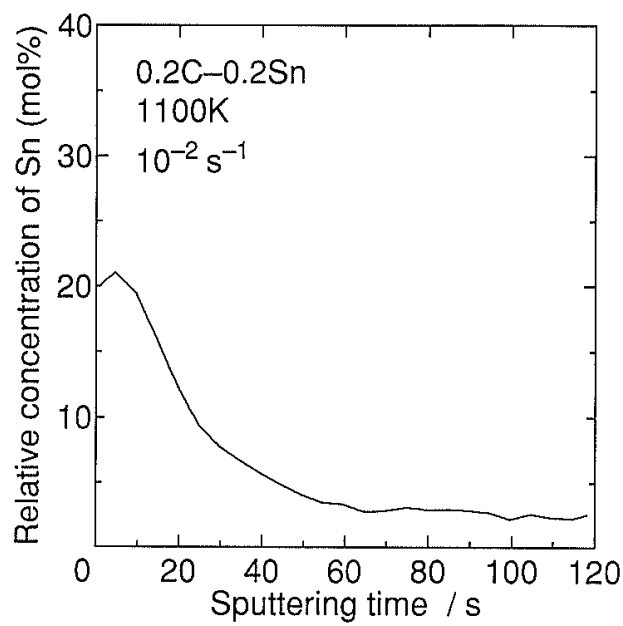

Fig. 12. Depth profile of tin content from grain boundary on fracture surface by sputtering with $\mathrm{Ar}+\mathrm{ion}$, for the steel $\mathbf{P}$ deformed at $1100 \mathrm{~K}$ and at $10^{-2} \mathrm{~s}^{-1}$.

The segregation of sulphur is observed on the intergranular decohesion fracture surfaces of the ultra-low carbon steel $\mathrm{F}$ and the intergranular ductile fracture surfaces of the $0.2 \%$ carbon steel $\mathrm{R}$. In both specimens, the sulphur content on the grain boundary surface $X_{\mathrm{S}}^{\mathrm{g}}$ is about $15 \mathrm{~mol} \%$ and total sulphur volume per unit area of the grain boundary $Y_{\mathrm{S}}^{\mathrm{g}}$ is estimated to be $1.0 \times$ $10^{-7} \mathrm{~mol} \% \mathrm{~m}$. However, the grain boundary segregation of copper atoms was not observed for both steels. The segregation of copper was also not observed on the intergranular ductile fracture surfaces for the steel $O$.

It can be concluded that tin and sulphur cause the grain boundary segregation for the steels studied here, and, by contrast, copper does not segregate at the grain boundary in steels.

\section{Discussion}

\subsection{Mechanism of Intergranular Embrittlement}

The high-purity, ultra-low carbon steels exhibit comparatively good ductility by decreasing sulphur content. For both ultra-low carbon steels and $0.2 \%$ carbon steels, which are deformed in the lower austenite temperature range at higher strain rates, the addition of sulphur causes the embrittlement in intergranular de- 
cohesion fracture mode. The ductility of $0.2 \%$ carbon steels decreases at low strain rates in the temperature range from ferrite formation to lower austenite. With decreasing strain rate, intergranular decohesion fracture mode is transformed into intergranular ductile one and the number of cracks increases.

For specimens that experienced brittle fracture, the curves of reduction in area with temperature for each steel are classified in terms of additive element and strain rate, as shown in Fig. 13. The embrittlement can be here classified into two types: (1) embrittlement at high strain rates in the lower austenite temperature range of about $1180 \mathrm{~K}$; (2) embrittlement at low strain rates between the ferrite formation temperature range of about $1080 \mathrm{~K}$ and the lower austenite temperature range.

The former type of embrittlement at high strain rates occurs in steels containing sulphur, whereas it is not observed for steels without sulphur. The embrittlement takes place severely for higher strain rates, while the ductility at $200 \mathrm{~s}^{-1}$ decreases only around $1230 \mathrm{~K}$. The intergranular decohesion fracture surface, on which grain boundary segregation of sulphur atoms is verified, is observed in brittle specimens. In plain carbon steels, the ductility is improved in the lower austenite temperature range higher than the $\mathrm{Ar}_{3}$ by $100 \mathrm{~K}$ and isothermal holding on the way cooling from solution treatment temperature also increases the ductility. Through the brittle behaviour and the recovery of ductility, the cause of the embrittlement is considered to be grain boundary segregation of sulphur. ${ }^{11}$ The reaction of the segregated sulphur with iron leads to form the fine precipitation of sulphide, which breaks from matrix by tensile deformation. The coalescence of microvoids initiated at the sulphides forms cracks, and leads to intergranular fracture.

The second type of embrittlement at low strain rates occurs mainly for the plain carbon steels, and it is severe for the steel containing sulphur or tin. The ductility becomes minimum in the lower austenite temperature range just above the $\mathrm{Ar}_{3}$, and it decreases with decreasing strain rate. Most of fracture surfaces are intergranular ductile and the cracks are observed along the austenite grain boundary. The grain boundary segregation of tin or sulphur atoms is observed on the intergranular ductile fracture surface. However, no crack is observed on the proeutectoid thin-film ferrite formed along the grain boundary at the ferrite formation temperature. Through

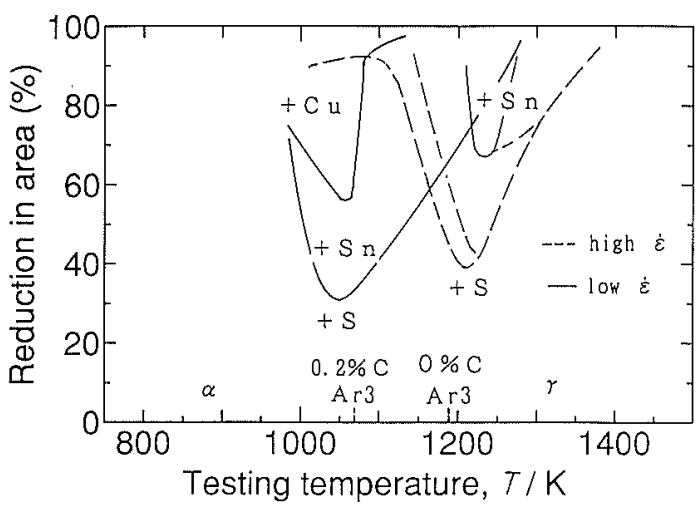

Fig. 13. Variation of reduction in area with temperature for various carbon steels showing low ductility. the fracture mode and the variation of reduction in area with temperature and strain rate, the cause of the embrittlement is considered to be pile-up of dislocations at the austenite grain boundary. ${ }^{12)}$ In the low speed deformation process, incompatibility or the difference in the deformation near the grain boundary generates dislocations, which can be annihilated by vacancy diffusion to the grain boundary. However, microvoid nucleation annihilates the incompatibility, as long as grain boundaries are immobile owing to locking by segregation of impurities. The growth and coalescence of microvoids are promoted, which leads to intergranular fracture.

Next, the recovery of ductility at higher temperatures of austenite range will be discussed. Grain boundary migration can easily occur with increasing temperature in the austenite temperature range, leading to improving ductility by diminishing the microvoid nucleation. However, the grain boundary migration is difficult to find experimentally. On the other hand, hot ductility generally becomes excellent by dynamic recrystallization. Both grain boundary migration and dynamic recrystallization depend on volume diffusion, and grain boundary migration occurs at lower temperatures than dynamic recrystallization. Therefore, grain boundary migration can be estimated by investigating dynamic recrystallization.

Generally, whether dynamic recrystallization occurs or not can be judged by stress-strain curves or microstructures. Here, as a simpler method for the judgment, the strain to the peak stress in stress-strain curves is used. Dynamic recrystallization causes the decrease in the strain to the peak stress. ${ }^{13}$ ) The variations of the strain to the maximum stress with temperature for the steels $\mathrm{O}$ and $\mathrm{P}$ deformed at $10^{-2} \mathrm{~s}^{-1}$ are shown in Fig. 14. With increasing temperature, the strain hardly decreases for the steel containing tin, whereas it decreases rapidly for the steel containing copper. The intergranular embrittlement in the lower austenite temperature range at lower strain rates is eliminated by grain boundary migration and dynamic recrystallization at higher temperatures. The ductility of the steel containing copper is apparently improved with decreasing the strain.

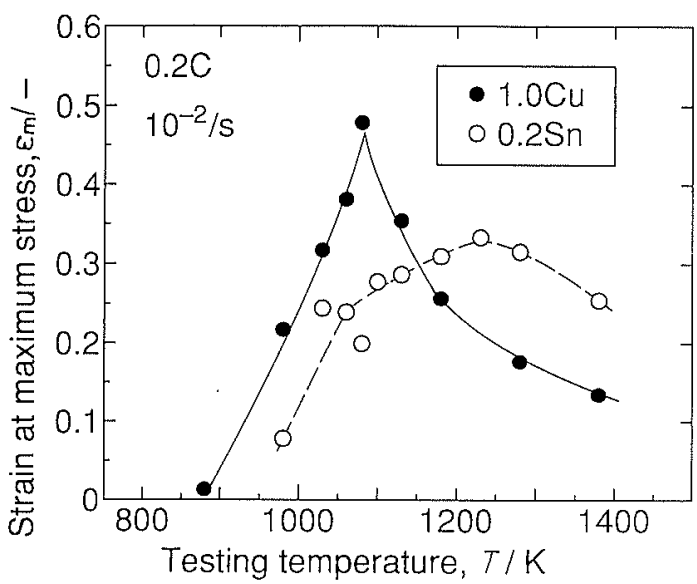

Fig. 14. Variation of strain to the maximum stress with temperature for the steels $\mathrm{O}$ and $\mathrm{P}$ deformed at $10^{-2} \mathrm{~s}^{-1}$ 
The ductility is improved at the ferrite formation temperatures for all cases. This is because the formation of ferrite on the grain boundaries eliminates austenite grain boundaries and restrains crack initiation. The transformation associated with bulk diffusion will diminish the incompatibility across the austenite grain boundary.

\subsection{Effect of Carbon on Hot Ductility}

The brittle behaviour of ultra-low carbon steels and $0.2 \%$ carbon steel is necessary to be discussed individually since the matrices are different. Here, the embrittlement at low strain rates is discussed for the case that sulphur is not present or the effect is ignored.

On the basis of the equilibrium phase diagram of $\mathrm{Fe}-\mathrm{C}$ system, the equilibrium transition temperature from austenite to ferrite $\mathrm{Ae}_{3}$ is $1180 \mathrm{~K}$ for ultra-low carbon steels. The austenite-ferrite dual phase region is narrow and the structure is transformed from austenite single phase to ferrite. The ductility is improved below $\mathrm{Ae}_{3}$ point because of ferrite formation. The strain to the maximum stress at $10^{-2} \mathrm{~s}^{-1}$ for the various ultra-low carbon steel is shown in Fig. 15. For the steel without copper and tin, dynamic recrystallization occurs at $1230 \mathrm{~K}$, which is above the $\mathrm{Ar}_{3}$. Compared with this steel, the steel containing copper or tin has larger strain to the peak stress at this temperature, and then the ductility decreases by restraint of dynamic recrystallization. However, even for the steel containing copper and tin, the ductility is improved at $1280 \mathrm{~K}$ and above by dynamic recrystallization. Therefore, the embrittlement at low strain rates in the temperature range between ferrite formation and lower austenite is difficult to occur for ultra-low carbon steels.

On the other hand, austenite-ferrite dual region appears by carbon addition and the $\mathrm{Ar}_{3}$ temperature decreases with increasing carbon content. In other words, the austenite temperature range is extended to lower temperatures and ferrite formation temperature decreases. The $\mathrm{Ae}_{3}$ temperatures are 1090 and $1110 \mathrm{~K}$ for the $0.2 \%$ carbon steels with and without copper, respectively. The $\mathrm{Ar}_{3}$ temperature of $0.2 \%$ carbon steels are lower than that of ultra-carbon steels by $100 \mathrm{~K}$. In

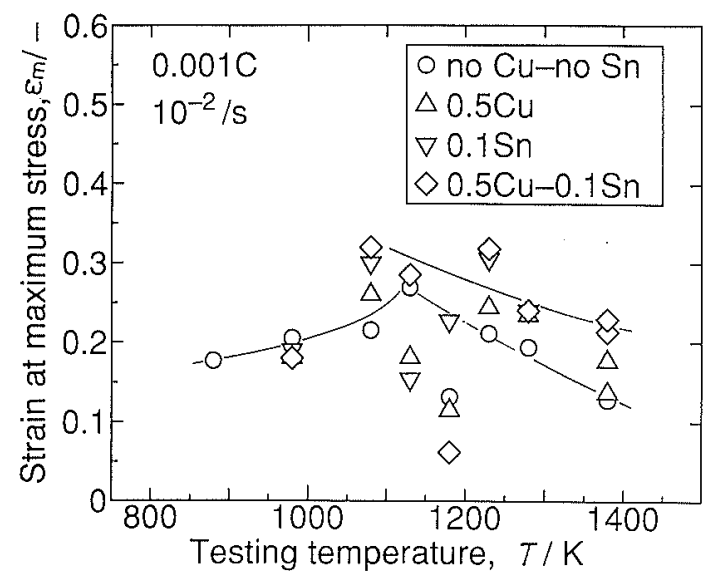

Fig. 15. Variation of strain to the maximum stress with temperature for the ultra low carbon steel and $0.14 \%$ carbon steel deformed at $10^{-2} \mathrm{~s}^{-1}$.
$0.2 \%$ carbon steels, dynamic recrystallization is difficult to occur just above the $\mathrm{Ar}_{3}$ temperature. Furthermore, the dynamic recrystallization in commercial steels is impeded by additive elements. ${ }^{14,15)}$ In the lower austenite temperature range, dynamic recrystallization does not occur even at a low strain rate of $10^{-2} \mathrm{~s}^{-1}$. Therefore, the temperature range in which the ductility is low is extended to lower temperature side with increasing carbon content.

In the ductility curves of the steels containing tin shown in Fig. 13, the temperature, at which the ductility starts to fall with decreasing temperature, for the ultra-low carbon steels is comparable with the temperature for the $0.2 \%$ carbon steel. The brittle temperature range of the $0.2 \%$ carbon steel is extended to lower temperature side, compared with the ultra-low carbon steel. This implies that the ductility trough by tin addition is dependent on carbon content.

\subsection{Effect of Tin and Copper on Hot Ductility}

Tin plays a role of impeding grain boundary migration by grain boundary segregation since the presence of tin atoms retards dynamic recrystallization.

The grain boundary segregation by tin is discussed. The grain boundary enrichment ratio $\beta$ is given by the following equation. ${ }^{16)}$

$$
\beta=X_{\mathrm{Sn}}^{\mathrm{b}} / X_{\mathrm{Sn}}^{\mathrm{m}}
$$

where $X_{\mathrm{Sn}}^{\mathrm{b}}$ and $X_{\mathrm{Sn}}^{\mathrm{m}}$ are the molar fraction of tin at grain boundary and in matrix, respectively. $X_{\mathrm{Sn}}^{\mathrm{b}}$ is 0.21 by AES analysis and $X_{\mathrm{Sn}}^{\mathrm{m}}$ is $9.00 \times 10^{-4}$ by the composition. Hence $\beta$ is calculated to be 230 . The solid solubility of tin in the matrix is denoted by $X_{\mathrm{Sn}}^{\mathrm{O}}$. For example, $X_{\mathrm{Sn}}^{\mathrm{O}}$ is $7.5 \times 10^{-3}$ at $1373 \mathrm{~K}^{17)}$ and it is $7.8 \times 10^{-3}$ at $1473 \mathrm{~K}^{18)}$ The free energy of grain boundary segregation by tin $\Delta G_{\mathrm{Sn}}^{\mathrm{b}}$ is estimated by the following equation, ${ }^{19)}$

$$
X_{\mathrm{Sn}}^{\mathrm{b}} /\left(1-X_{\mathrm{Sn}}^{\mathrm{b}}\right)=X_{\mathrm{Sn}}^{\mathrm{m}} \exp \left(-\Delta G_{\mathrm{Sn}}^{\mathrm{b}} / R T\right) / X_{\mathrm{Sn}}^{\mathrm{O}},
$$

since $X_{\mathrm{Sn}}^{\mathrm{m}}$ is smaller than $X_{\mathrm{Sn}}^{\mathrm{o}} . \Delta G_{\mathrm{Sn}}^{\mathrm{b}}$ is calculated to be $-9 \mathrm{~kJ} / \mathrm{mol}$ at $1373 \mathrm{~K}$ and $-10 \mathrm{~kJ} / \mathrm{mol}$ at $1473 \mathrm{~K}$. The diffusion coefficient of tin in austenite iron is $1.6 \times$ $10^{-13} \mathrm{~m}^{2} / \mathrm{s}$ at $1580 \mathrm{~K}^{20}$ ) The grain boundary segregation by tin is possible by lattice diffusion during the heating treatment in the austenite temperature range.

The plain carbon steel containing copper shows a ductility trough at the ferrite formation temperatures, but copper does not cause grain boundary segregation. Dynamic recrystallization occurs even in the lower austenite temperature range for the steel containing copper. Then, it is thought that copper does not impede dynamic recrystallization by no segregation at grain boundaries. This is due to the higher solubility and slow diffusion rate of copper in the austenite iron. Copper is completely dissolved in the austenite matrix since the solubility of copper is $3.4 \mathrm{~mol} \%$ at $1173 \mathrm{~K}^{21)}$ The diffusion coefficient of copper in austenite iron is $2.5 \times 10^{-14} \mathrm{~m}^{2} / \mathrm{s}$ at $1588 \mathrm{~K},{ }^{22)}$ which is one seventh of that of tin at the same temperature. Addition of copper decreases the transition temperature from austenite to ferrite by $20 \mathrm{~K}$, but the effect is small. 


\section{Conclusion}

The effect of copper and tin on the hot ductility of the steels was investigated by hot tensile test in vacuum in the temperature range between higher ferrite and lower austenite at the strain rates ranging from $10^{-2}$ to $200 \mathrm{~s}^{-1}$.

(1) For the ultra-low carbon steel without containing copper and tin, the ductility is good. The addition of both copper and tin slightly decreases the ductility in the lower austenite temperature range at all strain rates. The addition of tin slightly decreases the ductility in the lower austenite temperature range at high strain rates.

(2) Addition of sulphur to ultra-low carbon steels causes a ductility trough in the lower austenite temperature range at high strain rates regardless copper addition.

(3) For the steels containing $0.2 \%$ carbon, the ductility is not affected by the addition of copper. The addition of tin decreases the ductility in the lower austenite temperature range at low strain rates. This is because tin can cause grain boundary segregation and impedes grain boundary migration, whereas copper does not have such detrimental effects.

(4) The ductility of the $0.2 \%$ carbon steels decreases in the lower austenite temperature range by the addition of sulphur.

(5) The embrittlement at high strain rates for steels containing sulphur is due to grain boundary segregation of sulphur.

(6) The embrittlement at low strain rates in the temperature range between ferrite formation and lower austenite is due to the pile-up of dislocations at the grain boundary and retardation of grain boundary migration by segregants such as tin and sulphur. As long as the grain boundary is immobile, vacancy diffusion to the grain boundary for annihilating dislocations leads to the formation and the coalescence of microvoids.

\section{Acknowledgement}

The authors would like to thank Mr. K. Ohsawa,
Materials Research Center, NKK Corporation for supplying the hot-rolled plates.

\section{REFERENCES}

1) D. T. Llewellyn, J. B. Marriott, D. J. Naylor and G. Thewlis: Residuals, Additives and Materials Properties, The Royal Soc., London, (1980), 69.

2) J. A. Vallomoy: Ind. Heat., 52 (1985), 34.

3) H. G. Suzuki, S. Nishimura and S. Yamaguchi: Trans. Iron Steel Inst. Jpn., 22 (1982), 48.

4) R. Abu-shosha, R. Vipond and B. Mintz: Mater. Sci. Technol., 7 (1991), 1101.

5) D. Smith, A. Nicholson and J. D. Murray: J. Iron Steel Inst., 210 (1972), 412.

6) D. A. Melfold: Philos. Trans. R. Soc. (London) A, 295 (1980), 89.

7) N. E. Hannerz: Trans. Iron Steel Inst. Jpn., 25 (1985), 149.

8) C. Rossard and P. Blain: Rev. Metall., 56 (II) (1959), 175.

9) W. J. Jackson and D. M. Southall: Philos. Trans. R. Soc. (London) $A, 295$ (1980), 125.

10) B. Mintz, R. Abu-shosha and D. N. Crowther: Mater. Sci. Technol., 11 (1995), 474.

11) C. Nagasaki, A. Aizawa and J. Kihara: Trans. Iron Steel Inst. Jpn., 27 (1987), 506.

12) P. Sricharoenchai, C. Nagasaki and J. Kihara: ISIJ Int., 32 (1992), 1102.

13) M. J. Luton and C. M. Sellars: Acta Metall., 17 (1969), 1033.

14) C. Ouchi and T. Okita: Trans. Iron Steel Inst. Jpn., 22 (1982), 543.

15) H. L. Andrade, M. G. Akben and J. J. Jonas: Metall. Trans., 14A (1983), 1967.

16) M. P. Seah: Practical Surface Analysis by Auger and X-ray Photoelectron Spectroscopy, ed. by D. Briggs and M. P. Seah, John Wiley \& Sons Ltd., Sussex, (1983), 247.

17) M. Hillert, T. Wada and H. Wada: J. Iron Steel Inst., 205 (1967), 539.

18) E. A. Speight: Met. Sci. J., 6 (1972), 57.

19) M. P. Seah and E. D. Hondros: Proc. R. Soc. (London) A, 335 (1973), 191.

20) M. Arita, M. Ohyama, K. S. Goto and M. Someno: Z. Metallkd., 72 (1981), 244.

21) M. Hasebe and T. Nishizawa: Calphad, 4 (1980), 83.

22) S. J. Rothman, N. L. Peterson, C. M. Walter and L. J. Nowicki: J. Appl. Phys., 39 (1968), 5041 